\title{
RESENHA
}

\section{UMA PONTE SUSPENSA ENTRE A EUROPA E A AMÉRICA: OS AÇORES E A GEOPOLÍTICA DO ATLÂNTICO NORTE NA LEITURA DE JOSÉ MEDEIROS FERREIRA}

\section{Daniel de Oliveira Cunha ${ }^{1}$}

Resenha DE: FERREIRA, José Medeiros. Os AÇORES na POLÍTICA INTERNACIONAL: elementos. Lisboa: Tinta da China, 201 1, 181 P.

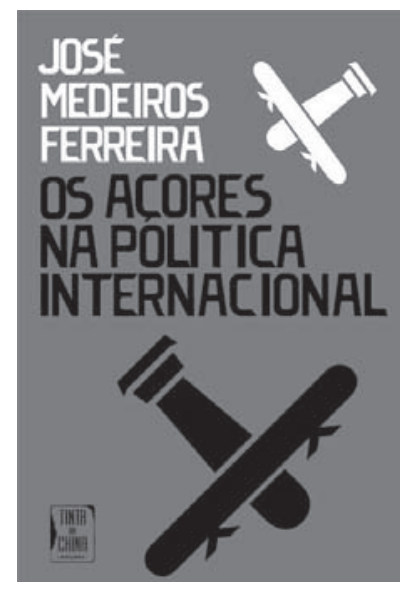

Recentemente falecido, o historiador português José Manuel de Medeiros Ferreira (1942 - 2014) foi uma das principais figuras da política portuguesa no último meio século. Iniciou sua atuação neste campo como representante acadêmico durante as crises estudantis dos anos sessenta, interrompida após sua detenção e expulsão da universidade em 1965. Nessa altura, advogava a autodeterminação das colônias africanas, e por ironias da vida chegou a dividir a cela da prisão com o nacionalista angolano Joaquim Pinto de Andrade. Esteve exilado na Suíça durante todo o período do marcellismo (1968 - 1974), de onde editou a revista de militância Polémica e idealizou o programa dos três Ds (Democratização, Descolonização e

Pós-graduando pela Faculdade de Direito da Universidade de São Paulo. Pesquisador do Centro de Estudos Rurais e Urbanos (CERU), do Centro de Estudos Africanos (CEA) e do grupo IMARGENS (Sociologia - USP). 
Desenvolvimento), logo adotado pelo Movimento das Forças Armadas. Após a Revolução dos Cravos, participou do primeiro Governo Constitucional de Portugal ao lado de Mário Soares, como eminente membro do Partido Socialista, como deputado à Assembleia Constituinte (1975 - 1976) e como ministro dos Negócios Estrangeiros entre 1976 e 1978.

Na qualidade de especialista em história contemporânea de Portugal, analista de política internacional e memorialista político, publicou quinze livros e dezenas de capítulos, artigos acadêmicos e textos jornalísticos. Um de seus temas de predileção era a geopolítica dos Açores, o arquipélago onde tivera seu nascimento registrado (nasceu na Madeira) e passara suas primeiras décadas de vida e de formação. Além de partidário da autonomia regional açoriana e madeirense, era ainda um dos mais influentes defensores da integração portuguesa à Comunidade Europeia - e por isso foi apelidado de "senhor Europa". Em síntese, ao longo de seu multifacetado percurso, preocupou-se com a conciliação, nos planos teórico e prático, dos diversos e contraditórios interesses envolvidos entre as escalas regionais, nacional, europeia e transatlântica, harmonização esta que veio a se confirmar "por fases mais ou menos prósperas, mais ou menos felizes (...) como um período de constante sucesso" (p. 147). No entanto, como Medeiros Ferreira já teve a ocasião de apresentar em seus estudos historiográficos, se o desenlace da história portuguesa recente resultou em inquestionável calmaria, não o foi sem passar por um tormentoso percurso em que muitos elementos nacionais e internacionais ameaçaram entrar em rota de colisão - e um dos cenários desse potencial entrechoque foi precisamente o conjunto de ilhas dos Açores.

Seu primeiro livro dedicado especificamente ao "arquipélago colorido" é A autonomia dos Açores na percepção espacial da comunidade portuguesa (Ponta Delgada: Jornal de Cultura, 1995). Um desdobramento do mesmo tema, aqui resenhado, resultante de sua atividade universitária subsequente na Universidade dos Açores, foi publicado pela editora lisboeta Tinta da China em 2011, e intitulado Os Açores na política internacional. A obra está repleta de jogos de palavras que apontam os lugares particulares e as cambiantes posições estratégicas atribuídas às ilhas em sucessivas conjunturas históricas. Ora enfatiza-se sua inserção no "espaço euro-atlântico" (p. 12) ou "cisatlântico" (p. 106), como no momento atual, ora é objeto das "decisões transatlânticas" (p. 97), como na época da Guerra Fria. Ao servir-se de uma bem concebida metáfora meteorológica, baseada nos processos atmosféricos que regem a orientação dos ventos insulares ${ }^{2}$, Medeiros Ferreira assim condensa acerca dessa conjunção ambivalente, auspiciosamente tendente a um tênue, mas contínuo equilíbrio de forças, ou

Metáfora esta oportunamente destacada em uma recensão à mesma obra: RILEY, Carlos. "A isóbare dos Açores", Relações Internacionais, 32, Lisboa, p. 199-204, dezembro de 2011. 
seja, ao já mencionado "período de constante sucesso": "Em termos prospectivos podemos vir a assistir à formação de uma espécie de isóbare [isto é, de igual ou constante pressão] na atmosfera açoriana entre correntes mais continentalistas e massas de ar mais atlantistas" (p. 106).

Ao longo dos últimos duzentos anos, os Açores estiveram sob três sucessivas esferas de influência estrangeira. Entre 1808 e 1917, a GrãBretanha ocupou-se da segurança dessa área; de 1917 a 1991, essa atribuição foi transferida aos Estados Unidos; por fim, a partir de fins dos anos oitenta, até aos dias atuais, há uma passagem progressiva da assistência financeira estadunidense para a Comunidade Europeia. De qualquer modo, a histórica aliança atlântica - "triângulo negocial" (p. 90) - entre Lisboa, Londres e Washington manteve-se mais ou menos bem articulada, mesmo durante os momentos de tensão contingencial seja entre esses três centros de poder, seja em situações de intrusão por parte de outros tantos.

Neutralidade transatlântica colaborante: Estados Unidos, Grã-Bretanha E PORTUGAL $^{3}$

Medeiros Ferreira estabelece um contraste revelador entre as políticas exteriores de Portugal e dos Estados Unidos, primeiramente em relação à defesa da liberdade dos mares, ao menos desde o século XIX ${ }^{4}$, e em segundo lugar com referência à declaração de neutralidade durante os conflitos armados entre terceiros países. As duas questões estão entrelaçadas, uma vez que a liberdade de comércio dos neutros implica no direito ao livre comércio com quaisquer beligerantes. No entanto, a presunção da neutralidade sempre sofreu violações por parte das potências hegemônicas e semihegemônicas: durante as guerras napoleônicas, Portugal esteve sob a ocupação francesa, entre 1808 e 1814, ao passo que os Estados Unidos foram invadidos pela Grã-Bretanha em 1812 (p. 85).

Nas décadas seguintes ao Congresso de Viena, a neutralidade foi em vários momentos declarada entre ambos os países, e nesses casos genericamente reconhecida: na Guerra da Crimeia (1855), na Guerra Franco-

\footnotetext{
O autor não faz menções mais extensas ao Brasil, mas um paralelo com este país sul-americano poderia ser perfeitamente apresentado nesse pequeno livro, com o hipotético ganho adicional da ampliação de continuidade subjacente às políticas de segurança não apenas do Atlântico Norte, mas do oceano como um todo. Sobre a negligência dos países do norte com relação às demandas próprias dos países do Atlântico Sul, ver RODRIGUES, José Honório. Brasil e África: outro horizonte. Rio de Janeiro: Civilização Brasileira, 1961 (esp. Cap. 7, "Brasil, Atlântico e África").

$4 \quad$ No caso de Portugal, nem sempre houve essa defesa da liberdade dos mares. É bem conhecida a controvérsia do século XVII entre a doutrina do mare liberum de Hugo Grócio e a doutrina do mar português, do Frei Serafim de Freitas, ainda defendida em alguns círculos acadêmicos durante o salazarismo e mesmo após sua queda. Ver CAETANO, Marcello. Introdução. FREITAS, Frei Serafim de. Do justo império asiático dos portugueses. Volume I. Lisboa: Instituto Nacional de Investigação Científica, 1983, p. 7-61.
} 
Prussiana (1870-1), na Guerra Hispano-Americana de 1898 (no caso de Portugal), e por fim na Guerra Anglo-Boer (1899-1902). Nos primeiros anos da Primeira Guerra Mundial, a condição de países neutrais foi novamente apreciada, mas, com o recrudescimento do conflito, ambos os países foram forçados a declarar guerra ao Eixo - Portugal em 1916, por pressão inglesa e interesse em embarcações alemãs atracadas em seus portos, e os EUA em 1917, após os torpedeamentos alemães à sua frota mercante. É justamente no segundo semestre de 1917 que os Açores passam à esfera de influência direta norte-americana, quando é negociada a construção da base naval de Ponta Delgada (ilha de São Miguel), com a corroboração da GrãBretanha (p. 88). Assim, os Estados Unidos expandiam o seu cinturão de segurança continental em direção ao "Atlântico profundo".

Durante a Segunda Guerra Mundial, os Açores voltaram novamente ao centro das atenções, como linha de defesa indispensável aos Aliados contra as potências do Eixo. Uma nova base naval, desta vez na ilha de Santa Maria, a Base das Lajes, originalmente de natureza bilateral, foi construída pelos americanos em 1944. ${ }^{5}$ Durante a Guerra Fria, e após a instituição da Organização do Tratado do Atlântico Norte (OTAN) em 1949, a utilização da Base das Lajes foi renovada cinco vezes (duas durante o governo de Salazar, em 1957 e 1962, uma durante o de Marcello Caetano, em 1969, e duas após a democratização, em 1979 e 1985).

\section{Separatismo E A EQUAÇÃo Açores VERSUS COLÔNIAS AFRICANAS ${ }^{6}$}

Em 1962, é de conhecimento geral que Salazar usou barganhou a renovação da Base das Lajes para obter o apoio dos Estados Unidos já no início da guerra de independência de Angola. No entanto, como lembra Medeiros Ferreira, "é preciso enquadrar o pensamento dos EUA na hierarquia dos interesses no exterior. E, nessa hierarquia, a utilização dos Açores há muito tempo que era mais urgente do que uma independência imediata

\footnotetext{
Uma observação adicional, apontada pelo General Pedro Cardoso em outra publicação sob a coordenação de Medeiros Ferreira, revela que Franklin Roosevelt, em uma conferência de imprensa, pouco antes de sua morte, havia sugerido uma das ilhas do arquipélago para sede das Nações Unidas. Ver CARDOSO, General Pedro. "Antecedentes e repercussões da entrada de Portugal na OTAN". FERREIRA, José Medeiros (Coord.). Política externa e política de defesa do Portugal democrático. Lisboa: Edições Colibri; Fundação Mário Soares; Instituto de História Contemporânea da Universidade Nova de Lisboa, 2001, p. 145.

6 Não houve, nem nos Açores, nem nas ilhas da Madeira, um nacionalismo independentista e de esquerda nem de longe semelhante ao das possessões insulares de Portugal ao sul do trópico de Câncer (PAIGC em Cabo Verde, e CLSTP/MLSTP em São Tomé e Príncipe). Já as Ilhas Canárias, pertencentes à soberania da Espanha, não tiveram um movimento separatista conservador como o daqueles arquipélagos norte-atlânticos, mas de esquerda revolucionária, resumida à quase solitária militância de Antonio Cubillo, fundador do Movimiento por la Autodeterminación e Independencia del Archipiélago Canario (MPAIAC) e exilado político na Argélia por mais de duas décadas, bastante conhecido pelos militantes de esquerda africanos e latino-americanos que buscaram abrigo e treinamento militar em acampamentos argelinos desde 1962.
} 
dos territórios africanos acordada por Portugal" (p. 92). A competente equipe diplomática da era Kennedy (representada por Kenneth Galbraith, George Ball, entre outros) havia feito a previsão, que se revelaria profética, de que as possessões ultramarinas portuguesas alcançariam sua independência no prazo de dez anos. Neste contexto, o arquipélago permaneceu como a pauta principal das relações entre Lisboa e Washington durante o regime autoritário português, relações estas seriamente abaladas apenas em 1973, quando Nixon ordenou unilateralmente a passagem pela Base de Lajes de mais de 1200 aviões carregados com material de guerra, em auxílio a Israel durante a Guerra do Yom Kippur.

Para além de uma conjuntura internacional em rápida e conturbada alteração, a Revolução dos Cravos alterou profundamente o quadro das relações estratégicas de Portugal, e as ilhas norte-atlânticas estiveram à frente das novas conversações que se estabeleceram com os aliados externos tradicionais. Durante o "Verão Quente" de 1975, surgiram dois movimentos nos Açores e na Madeira que anunciavam publicamente a autodeterminação dos arquipélagos, a Frente de Libertação dos Açores (FLA) e a Frente de Libertação do Arquipélago da Madeira (Flama). Em abril do mesmo ano, o embaixador dos EUA em Lisboa, Frank Carlucci, transmitia ao Departamento de Estado a informação de que grupos portugueses exilados na Espanha, associados ao Movimento Açoriano para a Autonomia (MAPA) preparava uma ação armada nas ilhas, aconselhando Washington a manterse ao lado do governo português, caso isso fosse necessário (p. 98). Na mesma época, era denunciado o "Usine Plan", organizado desde os Estados Unidos por um operacional do grupo francês de extrema-direita Organisation de l'Armée Secrète (OAS), no sentido de desestabilizar politicamente as ilhas açorianas (p. 124).

Em endosso (hesitante) à recomendação de Carlucci, o próprio Secretário de Estado dos EUA, Henry Kissinger, concluiu pelo não encorajamento desses movimentos separatistas (p. 127). Porventura essa decisão tenha sido tomada prioritariamente em razão de outros fatores que não os de foco na estabilização política nacional. Entravam em jogo outros interesses geoestratégicos, para além daqueles propriamente dos países banhados pelo Atlântico Norte, sobretudo como um desdobramento indireto do primeiro Choque do Petróleo e do acréscimo de poder dos membros da OPEP. Em agosto de 1974, segundo um telegrama que chegara à Embaixada estadunidense em Lisboa, teria sido feita uma "oferta árabe" de 400 milhões de dólares ao governo provisório português, em troca da proibição de uma futura utilização da Base das Lajes durante situações de conflito militar no Oriente Médio (p. 97). Medeiros Ferreira situa o ano de 1978 como o início das aproximações da Argélia de Hourari Boumédiène e da Líbia de Muammar al-Qathafi junto aos separatistas. Por meio de declarações de "africanidade" dos Açores, da Madeira e das Canárias por repre- 
sentantes desses países, buscava-se ainda a neutralização dos arquipélagos como ponto de apoio logístico dos Estados Unidos para sua projeção geopolítica no Oriente Médio e no Golfo Pérsico, além do que a delicada questão do Saara Ocidental chegava ao auge de seu impasse. Não se exclui o interesse dos apoiantes estrangeiros das independências em transformar os territórios insulares em "paraísos fiscais" para suas atividades financeiras internacionais (p. 117). José de Almeida, presidente da FLA, ainda mencionava a ilha de Malta como "exemplo neutralista" a ser seguido após uma eventual secessão (p. 128).

INTEGRAÇÃO PORTUGUESA À EUROPA E AUTONOMIZAÇÃO DAS ILHAS NORTE-ATLÂNTICAS

Embora a FLA se mantivesse atuante até 1978 com a publicação de seu órgão de imprensa, O Milhafre (p. 127), e conservasse seu apoio internacional em razão da continuidade da receptação de recursos argelinos e líbios, ela já havia perdido sua capacidade de aliciamento local após a promulgação da Constituição portuguesa de 1976, cujos dispositivos agradaram aos anseios econômicos dos ilhéus ${ }^{7}$. O avanço institucional, no sentido da descentralização político-administrativa, fez eco aos dez pontos declarados pelo general Altino Pinto de Magalhães, então governador militar dos Açores, em solução de compromisso imediata com os manifestantes daquele que é considerado o maior protesto social da história açoriana na história recente - as chamadas manifestações de 6 de junho (de 1975), em Ponta Delgada -, e um dos maiores do "Verão Quente", no contexto nacional. Era precisamente o décimo ponto, cuidadosamente colocado ao fim de uma série de pendências econômicas e políticas mais imediatas, o que dizia respeito ao "Estudo do problema da definição de um estatuto de autonomia administrativa para o arquipélago" (p. 115).

Aquelas manifestações, no entanto, diziam respeito não tanto à secessão, mas ao próprio futuro da democratização portuguesa, visto que uma separação política "aparecia como uma forma radical de preservar a portugalidade conservadora, senão como uma maneira de a reconquistar no continente"». Toda essa movimentação política, segundo o Medeiros Ferreira,

\footnotetext{
Em seu Artigo 6", está estabelecido que "Os arquipélagos dos Açores e da Madeira constituem regiões autônomas dotadas de estatutos político-administrativos e de órgãos de governo próprio", e em seu Artigo $227^{\circ}$ ("Poderes das regiões autônomas") são enumeradas diversas garantias legislativas, orçamentárias e econômicas. Essas regiões podem até mesmo, como lembra Medeiros Ferreira, "participar de negociações de tratados e acordos internacionais que diretamente lhes diga respeito, bem como nos benefícios deles decorrentes", conforme o Artigo $229^{\circ}$ (p. 128).

8 As manifestações de 6 de junho, bem como a atuação da FLA, não estão muito distantes das de outros movimentos conservadores que surgiram no continente no mesmo período, em termos de objetivos políticos. Os mais atuantes foram o Exército de Libertação de Portugal (ELP), o Movimento Democrático de Libertação de Portugal (MDLP) e o Movimento Maria da Fonte. Esses movimentos não são mencionados no livro de Medeiros
} 
"foi ambivalente nos seus propósitos: tanto pretendeu moderar e domesticar a revolução desencadeada em Lisboa, como desenvolver uma perspectiva independentista, para se cristalizar no regime de autonomia político-administrativa regional" (p. 117), à medida que o "remate institucional da autonomia" ia moldando o papel e a relevância dos "gestores da transição" (p. 119).

Em todo caso, o ponto de equilíbrio entre Lisboa e os Açores levou um pouco mais de um ano para ser "aceite como uma nova base das relações entre o continente e os arquipélagos" (p. 127). Os Estados Unidos tiveram um papel relevante nessa nova conformação, a ponto de Frank Carlucci ter comparecido à sessão solene de abertura da Assembleia Regional dos Açores, em setembro de 1976 (p. 100). Aos poucos, a assistência financeira diretamente ao arquipélago pelos EUA era substituída pela da Comunidade Econômica Europeia. O ano de 1991 marca o início da chegada significativa de fundos comunitários aos Açores, no quadro de apoio às "regiões ultraperiféricas" da União Europeia (p. 103). No plano político local, as demandas mais radicais gradativamente desapareceram desde o início das negociações para a adesão de Portugal à CEE em 1977, tanto que a Região Autônoma dos Açores não fez nenhuma requisição de um estatuto separado, diferentemente das Ilhas Faroés, na ocasião da adesão da Dinamarca em 1973, e das Ilhas Canárias, durante o processo de entrada da Espanha, também ocorrida em 1986 (p. 102).

Desde o Tratado de Maastricht, de 1992, os Açores assumiram as seguintes características definidoras, em acumulação com os diplomas nacionais que regularam seu estatuto autonômico, e em consonância com o princípio da subsidiariedade (que procura tornar as decisões comunitárias as mais próximas de seus cidadãos) e com a teoria da descentralização: uma região insular, arquipelágica, atlântica, oceânica e ultraperiférica (p. 132). E o conceito de ultraperiferia o que suscita maiores debates, desde sua implantação já no Tratado de Roma de 1957, para os Départements d'Outre-Mer (DOM) da França - que são Martinica, Guadalupe e Guiana Francesa no Caribe, e a Ilha de Reunião, no Índico (p. 138-9) -, até sua consagração jurídica no Tratado de Amsterdã em 1997, quando os arquipélagos norte-atlânticos (Açores, Madeira e Canárias) também passaram a receber essa denominação e a receber recursos e incentivos específicos para programas de desenvolvimento.

Entre esses recursos estão os Quadros Comunitários de Apoio (QCA), responsáveis pela concessão de sucessivos e volumosos recursos financeiros aos Açores, com a finalidade de consolidar sua posição como plataforma científica e tecnológica mundial (p. 147). Esta é, aliás, uma tendência mais que secular, uma vez que, já em fins do século XIX, o arquipélago já era tratado pelas potências europeias, mormente a Grã-Bretanha, mais do que uma "plataforma logística" (p. 15), uma "âncora oceânica de equipamentos científicos e de aparelhos de tecnologia de ponta" (p. 20), já apre- 
sentando uma "dotação precoce de sistemas de comunicações" (p. 18), então os mais avançados à época.

Medeiros Ferreira, nas primeiras páginas de seu livro (p. 10), referiuse à velha repartição de "espaços de influência" - umas mais pró-europeias, outras mais pró-americanas - em cada uma das ilhas e respectivas capitais. Esse ponto de intersecção equilibra atualmente influências "que são atualmente de cooperação mas que podem vir a ser de competição e de disputa”. A competição dificilmente poderá ocorrer pela via do investimento em novas tecnologias, como ele afirma ao fim do livro, quando ele constata que "Já se observa uma espécie de isóbare atmosférica que se desloca, por enquanto, no sentido contrário ao das massas de ar" (p. 156). Em termos sociológicos, os Açores são muito mais que um ponto de fricção geopolítica intercontinental. $\mathrm{O}$ autor o reconhece, nas últimas e lapidares linhas de seu livro, quando assinala que "Por muito que a geografia impere, é o espírito humano que a compreende e utiliza". 


\section{NORMAS PARA A APRESENTAÇÃO DE ARTIGOS PARA PUBLICAÇÃO NA REVISTA CADERNOS CERU}

1. A revista Cadernos CERU aceita artigos inéditos para publicação.

2. O material para publicação deverá ser encaminhado para o e-mail do CERU (ceru@usp.br) no formatos *.doc ou *.docx (Word).

3. O nome do(s) autor(es) deverá ser acompanhado dos seguintes dados (em nota de rodapé):

$$
\begin{aligned}
& \text { - atividade que exerce } \\
& \text { - instituição a que pertence } \\
& \text { - titulação acadêmica } \\
& \text { - e-mail }
\end{aligned}
$$

Separadamente, o autor deverá encaminhar um número de telefone para contato.

4. Os artigos deverão ter de 15 a 30 laudas, digitadas em folha A4, fonte Times New Roman, tamanho 12, espaço entre linhas 1,5, margens: superior, inferior, esquerda e direita de $2,5 \mathrm{~cm}$. A redação deverá ter sido revista, pois não serão aceitos textos que precisarem de revisão gramatical.

5. Resumos entre 10 e 15 linhas no máximo, em português e inglês (revisto), acompanhados de três a seis palavras-chave. Se o artigo estiver escrito em espanhol, deverá haver resumo em português, espanhol e inglês.

6. Todos os artigos enviados serão submetidos à apreciação do Conselho Editorial da revista.

7. Tabelas e quadros deverão ter acima o número do quadro ou tabela, logo abaixo o título, ainda colocado acima da tabela ou do quadro, centralizado e sem borda lateral. Outras formas de ilustração, como gráficos, fotos, mapas etc., deverão ter sua fonte colocada à esquerda, logo abaixo da figura, e com título ainda abaixo e centralizado.

8. Nas notas de rodapé deverão constar apenas informações complementares e indicações de leituras complementares sobre o assunto tratado. As notas serão indicadas no corpo do texto em algarismo ará- 